\title{
Novel Needle for Intravitreal Drug Delivery: Comparative Study of Needle Tip Aspirates, Injection Stream and Penetration Forces
}

This article was published in the following Dove Press journal: Clinical Ophthalmology

\author{
Lyubomyr M Lytvynchuk (D) I,2,* \\ Goran Petrovski $\mathbb{D}^{3, *}$ \\ Adien Dam ${ }^{4}$ \\ Joep Hiemstra ${ }^{4}$ \\ Tobias Wimmer' \\ Iryna Savytska ${ }^{5}$ \\ Susanne Binder ${ }^{2,6}$ \\ Knut Stieger'
}

'Department of Ophthalmology, JustusLiebig-University Giessen, Eye Clinic,

University Hospital Giessen and Marburg

$\mathrm{GmbH}$, Campus Giessen, Giessen, Germany; ${ }^{2}$ Karl Landsteiner Institute for Retinal Research and Imaging, Vienna, Austria; ${ }^{3}$ Center of Eye Research, Department of Ophthalmology, Oslo University Hospital and Institute of Clinical Medicine, University of Oslo, Oslo, Norway; ${ }^{4}$ Vitreq B.V., MG

Vierpolders, the Netherlands;

${ }^{5}$ Department of Experimental Surgery, A. A.Shalimov National Institute of Surgery and Transplantology, National Academy of Medical Science of Ukraine, Kyiv, Ukraine; ${ }^{6}$ Department of Ophthalmology, Sigmund Freud University, Eye Center Donaustadt, Vienna, Austria

*These authors contributed equally to this work
Purpose: To study the efficacy of a novel needle for intravitreal injection (IVI) in comparison to the conventional needle under experimental conditions.

Methods: The newly designed 30-gauge (G) needle (NDN) (EP 18158 542.3, patent pending) with occluded outer orifice and a side port for drug delivery was compared to the conventional standard hypodermic $30 \mathrm{G}$ needle for IVI (SHN). An animal study to obtain needle tip aspirates was performed on 10 albino rat eyes. During IVIs, cellular content, which was cut by the needle tip, was aspirated. Cellular material was studied in regard to cell types and their quantity. The injection stream was studied using trypan blue dye in vitro and pig cadaver eyes. The penetration force was tested on polyurethane Testing Foil Strips PU 04 (Melab, Leonberg, Germany) by applying a velocity of $100 \mathrm{~mm} / \mathrm{min}$. The results were analyzed using descriptive statistics, correlation matrices and $t$-test methods with $p<0.05$ as statistically significant.

Results: Cytological analysis of the needle aspirates showed the presence of cellular content in each case. The amount of conjunctival, ciliary body epithelial cells and granulated basophilic protein sediments (sign of cellular damage) in the case of the NDN tips was significantly lower compared to the SHN. The average penetration force of the NDN was $0.791 \mathrm{~N}$, and in the case of the SHN was $0.566 \mathrm{~N}$. The injection stream study revealed a difference in the initial injection phase between the two needle types, although the diffuse filling of the vitreous area which surrounded the needle tip appeared to be similar.

Discussion: The NDN demonstrated superior performance with regard to a significantly reduced number of cells being captured by the needle tip. Delivery of the injected fluid into the vitreous cavity was comparable. In order to investigate superior properties of the NDN needle design, further studies with improved prototypes would be necessary.

Keywords: intravitreal injection, endophthalmitis, novel needle, needle tip, penetrating forces, injection stream

\section{Introduction}

Intravitreal injections (IVIs) of drugs have become a standard drug delivery technique aimed at carrying active pharmaceutical agents into the vitreous cavity. ${ }^{1-4}$ The vast majority of IVI is performed in order to inject anti-VEGF drugs for the treatment of agerelated macular degeneration (AMD) and other ocular conditions associated with increased concentration of VEGF. ${ }^{5-8}$ Furthermore, IVI of antibiotics, steroids, antiviral, antifungal and cytostatic agents is very important in the treatment of infectious eye diseases of different origin. ${ }^{6-9}$ In spite of the low risk for serious vision-threatening
Correspondence: Lyubomyr M Lytvynchuk Department of Ophthalmology, Justus-Liebig -University Giessen, Eye Clinic, University Hospital Giessen and Marburg GmbH, Campus Giessen, Friedrichstrasse 18,

Giessen, 35392, Germany

Tel +49 64198543820

Fax +49 64198543809

Email Lyubomyr.Lytvynchuk@augen.med. uni-giessen.de 
complications after IVI, the quantity of IVIs is progressively increasing worldwide, hence the number of patients experiencing IVI-associated complications is also increasing. ${ }^{10}$ Endophthalmitis is to one of the most dangerous complications following IVI. It can lead to irreversible loss of visual function and, in severe cases, loss of the affected eye with a risk of systemic dissemination of the infection. ${ }^{11-13}$ The rate of endophthalmitis remains between $0.018 \%$ and $1.4 \%$ of the patients treated with IVI, including infectious and noninfectious intraocular inflammation. ${ }^{13-19}$ Intrasurgical contamination of the ocular surface, needles and/or the therapeutic agent used have been considered to be the main causes of IVIassociated endophthalmitis. $^{20-23}$ The exact mechanism of intraocular contamination has, however, remained unclear.

Earlier we reported that the IVI technique using standard hypodermic needles leads to tissue damage of all eye wall layers (conjunctiva, sclera, ciliary body) due to the manufacturing technique itself. ${ }^{24,25}$ The inner sharp edge of the hypodermic needle appears to cut the cells that persist within the needle tip similar to fine needle aspiration biopsy. The cellular structures (autologous, and/or contaminated cellular material) which are captured by the needle tip consequently can be injected into the vitreous cavity and have the potential to contaminate and proliferate inside the vitreous body. ${ }^{26-28}$

There are a number of studies that analyze the causes of IVI-associated endophthalmitis and the mechanism of its development. $^{1,29-33}$ Different ways for reduction of endophthalmitis risk have been proposed after IVI. The latter can be differentiated into two main directions of needle improvement: reduction of the size of the needle, and improvement of the penetration properties of the needle. ${ }^{34-39}$ Additionally, new devices and new IVI techniques have also been proposed. ${ }^{40-44}$ However, all these methods employ a hypodermic (subcutaneous) type of needle tip.

This study aims to investigate the characteristics of a novel 30-gauge needle prototype designed specifically for IVI and to compare its performance with the standard hypodermic 30-gauge needle with regard to cellular content of the needle tip in experimental conditions, as well as the injection stream during IVI and penetration forces.

\section{Methods}

\section{Ethics Statement}

This study complied with the Guidelines of the Declaration of Helsinki and the ARVO statement for use of animals in ophthalmic and visual research. The study protocol for this experimental animal study was approved by the Ethical Committee of Department of Experimental Surgery at A.A. Shalimov National Institute of Surgery and Transplantology (National Academy of Medical Science of Ukraine, Kyiv, Ukraine) according to the rules of "Scientific and practical recommendations for hosting the animals and experimental work" of the Ministry of Health Care (Protocol \#5, from 19.06.2002) and The Law of Ukraine about defending animals from violence (№1759-VI from 15.12.2009).

\section{Novel Design of the Needle}

The concept of the newly designed 30-gauge $(\mathrm{G})$ needle (NDN) specifically for IVI use (EP 18158 542.3, patent pending) is depicted in Figure 1A and B.

In the experimental conditions of this study, the NDN was compared to a standard hypodermic $30 \mathrm{G}$ needle (SHN), which is regularly used for IVI (BD, Franklin Lakes, NJ, USA) (Figure 2A-C). Contrary to the SHN, the NDN possessed an occluded outer orifice and therefore absence of dead space inside the occluded tip, a side port with smooth rounded edges for drug delivery and a beveled tip (Figure 2D-I). During the study, only sterile single-use needles (NDN and SHN) were used.

Intraoperative spectral domain optical coherence tomography (iOCT) with Rescan ${ }^{\text {TM} 700 ~(C a r l ~ Z e i s s ~ M e d i t e c h, ~}$ Oberkochen, Germany) was used to image the tips of both needle types. This iOCT system, which is fully integrated into the surgical microscope OPMI Lumera 700, holds the following characteristics: OCT engine in the $\mathrm{Z}$ spectral domain, wavelength $840 \mathrm{~nm}$, scanning speed 27,000 A-scans per second, refresh rate with $5 \mathrm{~Hz}$ to $50 \mathrm{~Hz}$, axial resolution up to $3.5 \mu \mathrm{m}$ in tissue. The size of the iOCT scan was $2.5 \mathrm{~mm}$ in depth and $6.0 \mathrm{~mm}$ in length. A crosshair scan mode was used in order to image the surface of the needle tips (Figure 2B, E and H).

A schematic view of the needle tip was created with the use of graphic software CINEMA 4D (MAXON Computer $\mathrm{GmbH}$, Friedrichsdorf, Germany) (Figure 2C and F).

\section{Intravitreal Penetration and Aspiration in Rat Eyes}

The animal study was performed on 10 rat eyes of 10 Wistar white outbred albino rats (age: 6 months, weight: 600-800 g). General anesthesia was applied through subcutaneous injection of $0.2 \mathrm{~mL}$ of $1 \%$ solution of thiopental and $0.4 \mathrm{~mL}$ of $20 \%$ solution of oxybutyrate-Na. Cellular 
A
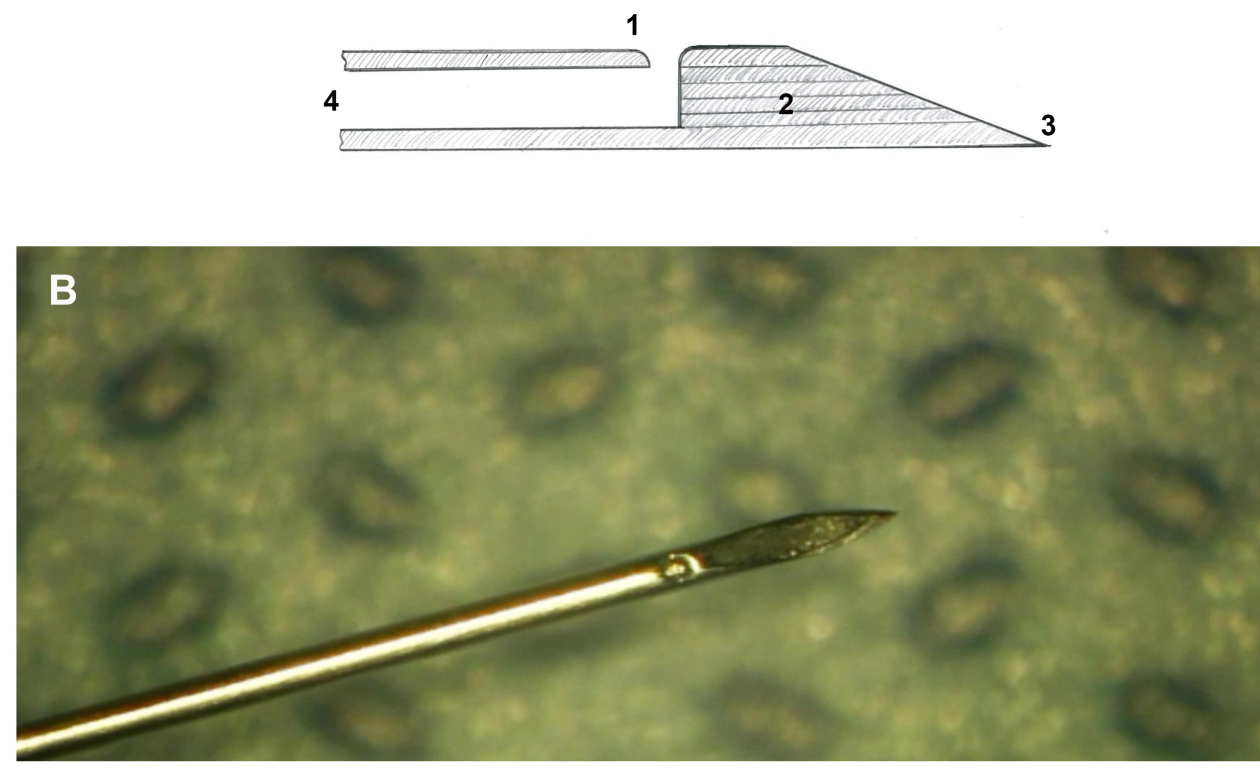

Figure I (A) Schematic drawing of the newly designed needle (NDN): I - side port with smooth edges for drug delivery; 2 - absence of the dead space; 3 - beveled tip with angle $18^{\circ} ; 4$ - caliber 30 gauge. (B) Enlarged view of the NDN prototype. (Created by L. Lytvynchuk.)

aspirates were obtained during the IVI technique for further analysis. The $1.0 \mathrm{cc}$ syringes were pre-loaded with $0.02 \mathrm{cc}$ of balanced salt solution (BSS) and connected to each needle in order to dissolve and flush out the aspirated cells. All IVIs were performed in the operating room of the animal facility under sterile conditions using an operating microscope. Only the right eye of animals was injected. Five IVIs were performed with each needle through the ciliary body $1 \mathrm{~mm}$ posterior to the limbus area in an oblique manner. During IVI, each needle was directed toward the central part of the retina. With the control of an operating microscope, the lens injury and peripheral retina damage could be avoided. After penetration with the needle instead of injection, aspiration of $0.01 \mathrm{cc}$ of vitreous body was performed, and then the needle was withdrawn from the eye. All animals were euthanized immediately after the IVI by an overdose of a $10 \%$ solution of sodium thiopental.

\section{Cytological Analysis of Needle Tip Aspirates}

Aspirated material was evacuated through the same IVI needle tip and onto glass slides, where it was fixed with $4 \%$ formalin and stained with azure-2-eosin. The number of each cell type was assessed in 30 equal visual fields in the shape of equal squares of $160 \mu \mathrm{m}^{2}$. The cells were recognized by their morphological characteristics accordingly. Cytological analysis was performed using a light microscope HD Microscope Camera CC50HD (Leica MikrosystemeVertrieb GmbH, Wetzlar, Germany) with magnification of $100 \times$ and $400 \times$. Cytological analysis was performed in order to identify and count separate cells (from conjunctiva, sclera, ciliary body, vitreous body) and the cellular complexes (granular proteins and conjunctival cell conglomerates). Separate cell counts were presented in numbers, and cellular complexes were estimated by their area of distribution in $1 \mu \mathrm{m}^{2}$. The granulated basophilic protein sediments were considered to be a result of cellular damage caused by tissue penetration during IVI. Conjunctival cell complexes were identified as the group of conjunctival cells still adherent to each other and suspended by a basal membrane.

The number of cells of each cell type from every needle tip aspirate was summarized for each needle type and then the data were analyzed statistically.

\section{Study of the Injection Stream During IVI}

In vitro. The injection stream from the two needle types was examined under the microscope using one SHN and one NDN. Two $2.0 \mathrm{~mL}$ syringes were prefilled with trypan 


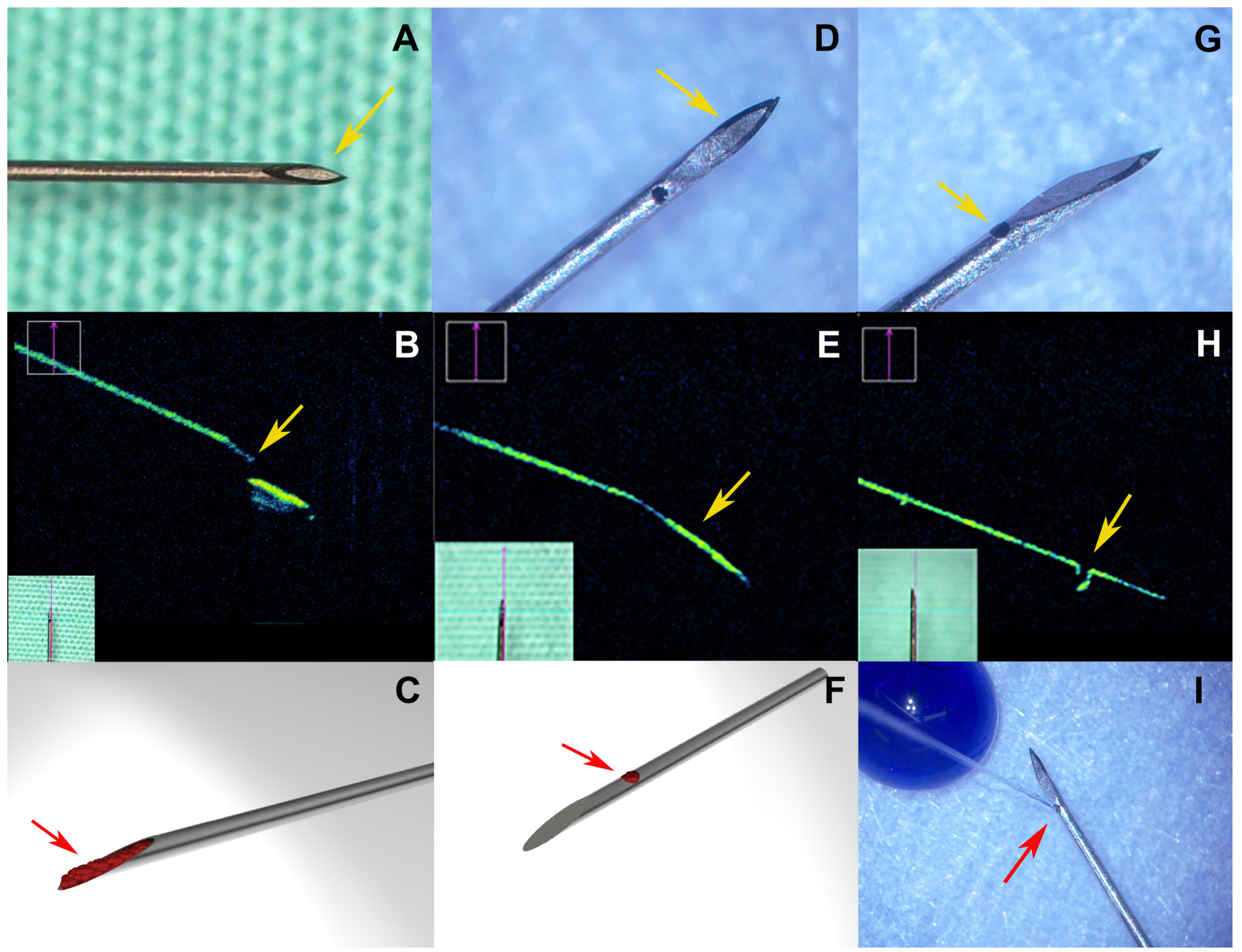

Figure 2 Overview of the two needle types used in the experimental study. Enlarged view of the standard hypodermic needle (SHN) $30 \mathrm{G}$ (A-C) and the newly designed needle (NDN) $30 \mathrm{G}$ (D-I). Yellow arrow indicates the presence of a front tip orifice in the SHN (A). iOCT of the SHN $30 \mathrm{G}$ needle (B) and NDN $30 \mathrm{G}$ needle (E and $\mathbf{H})$. (B) Yellow arrow indicates the sharp inner edge of the tip of the SHN. Yellow arrows indicate absence of the tip orifice (D and $\mathbf{E})$ and the side port (G and $\mathbf{H})$. (C and $\mathbf{F}$ ) Schematic view of the cellular content (red arrows) captured by the SHN 30 G and NDN 30 G needles, respectively. (I) The direction of the injection stream of the NDN (red arrow). (Created by L. Lytvynchuk.)

blue ophthalmic solution $0.06 \%$ Sida-Blue (IOL expert GmbH\&Co. KG, Bamberg, Germany) and connected to each needle type. Then, trypan blue ophthalmic solution was withdrawn through the needle by pressing the plunger of the syringe. The injection stream of each needle was documented with a video recording system.

\section{Cadaver Pig Eyes}

Six cadaver pig eyes were used for observational study of the injection stream during IVI. The cadaver eyes were placed on the surgical table and field using a standard eye surgery practice head (Idrees Eye Surgery Practice Head), which is designed to hold pig, sheep or cadaver eyes via suction for practicing surgical procedures (Gulden Ophthalmics Elkins Park, PA, USA).
Three needles of each type (SHN and NDN) were connected to the $2.0 \mathrm{~mL}$ syringes which were filled with trypan blue ophthalmic solution $0.06 \%$ Sida-Blue. One IVI of $0.1 \mathrm{~mL}$ of Sida-Blue was performed on every cadaver eye using one needle type.

The injection stream was examined and documented (video documentation) using E4 Ophthalmic Endoscopy System Endo Optiks ${ }^{\circledR}$ (BVI Medical, Waltham, MA, USA) with a 19-gauge ophthalmic endoscope. In each case, the IVI injection was performed $1 \mathrm{~mm}$ from the limbus at the 10 o'clock site of cadaver pig eyes in order to facilitate a comfortable position for the surgeon's right hand. Additional $1 \mathrm{~mm}$ sclerotomy was performed on the opposite side of the eye globe $1 \mathrm{~mm}$ from the limbus approximately at the 3 o'clock site with the purpose to introduce 
the 19-gauge ophthalmic endoscope. After the 19-gauge ophthalmic endoscope was introduced into the vitreous cavity and directed toward the pars plana region of the ciliary body, a conventional IVI was performed. The injection stream was video recorded and analyzed postoperatively.

\section{Study of Penetration Force}

The penetration force of the two needles was measured in Newtons $(\mathrm{N})$ and tested by positioning the needle tips perpendicularly at a distance of $1 \mathrm{~mm}$ from $0.4 \mathrm{~mm}$ thick polyurethane Testing Foil Strips PU 04 (Melab, Leonberg, Germany), and applying a velocity of $100 \mathrm{~mm} / \mathrm{min}$. The penetration resistance results were plotted as a loaddisplacement diagram. Each needle type was tested three times under constant conditions by three investigators, who were blinded to the standard and novel needle types.

\section{Statistical Analysis}

The results were analyzed statistically using descriptive statistics, correlation matrices and $t$-test methods. A $p$-value of $<0.05$ was counted to be statistically significant. The results were analyzed using the software STATISTICA 10 (StatSoft, Inc., OK, USA).

\section{Results}

\section{Novel Design of a Needle for IVI}

The general parameters of the NDN and SHN were similar: outer diameter $0.31 \mathrm{~mm}$, inner diameter $0.16 \mathrm{~mm}$, wall thickness $0.076 \mathrm{~mm}$, bevel degree $12^{\circ}$ (Abevel), length of $13 \mathrm{~mm}$ (stainless steel), and 30-gauge caliber (Figure 1B and Supplementary video 1). The NDN prototype was manufactured by $\mathrm{AD}$ and JH (Vitreq B.V., Vierpolders, The Netherlands) in cooperation with Mr. Didenko (Kyiv, Ukraine). The manufacture number of the needle prototypes was S190630G. The prototype of the NDN is not commercially available.

The main characteristics of the NDN prototype were the absence of the anterior orifice with sharp inner edges (Figure 1A and B; Figure 2D and E; Figure 3), and the presence of a side orifice (Figure 1A and B; Figure 2G and $\mathrm{H}$; Figure 3) which allowed for injection of drugs (Figure 2I and Supplementary video 2). On the contrary, the SHN had a distinct sharp inner edge, which was demonstrated with iOCT imaging (Figure 2B). This facilitated the mechanical cut of the tissue and capturing the cellular material (Figure 2C). ${ }^{24}$ The side port with smooth edges in the novel needle was designed to decrease the extent of tissue damage and cell capture (Figure 1A; Figure 2F).

\section{Cytological Study of the Needle Tip Aspirates}

During each IVI, the needle penetration caused damage of all tissues of the eye wall with resulted capture of tissue cells into the orifice of the needle tip.

Cytological analysis of the needle aspirates showed the presence of cellular content with each needle type, which consisted generally of conjunctival and ciliary body cells, granulated proteins, and vitreous body remnants (Figure 4). The amounts of conjunctival and ciliary body epithelial cells in NDN aspirates were about $50 \%$ less compared to the standard needle $(p<0.05)$ (Table 1). The amount of granulated basophilic protein sediments (sign of cellular damage), which were visualized with the azure-2-eosin staining, was $885.3 \mu \mathrm{m}^{2}$ for NDN cases and $1442.75 \mu \mathrm{m}^{2}$ for SHN cases (Table 1). Differences in the amount of conjunctival, ciliary body epithelial and granulated basophilic protein sediments which were obtained from the needle tips of the NDN and the SHN appeared to be statistically significant $(p<0.05)$.

\section{Injection Stream During IVI}

In vitro. Examination of the injection stream in the case of the SHN demonstrated a forwarddirected jet of the blue dye (Supplementary video 2). In the case of the NDN, the injection stream was directed in an oblique manner under an approximate angle of $75^{\circ}$ (Supplementary video 2).

\section{Cadaver Pig Eyes}

The experimental study of the injection stream during IVI on pig eyes revealed a difference in the initial stages of IVI during application of the two different needle types (Figure 5 and Supplementary video 3). During IVI with the SHN, the blue dye appeared at the end of the tip (Figure 5B). Consequently, the dye spread toward the vitreous cavity with a clearly visible jet, which was directed away from the needle tip (Figure 5C) and filled diffusely vitreous in the area of injection (Figure 5D and Supplementary video 3). During IVI with the NDN, the blue dye appeared first from the side opening (Figure 5F) and leaving the closed end of the needle tip free of 


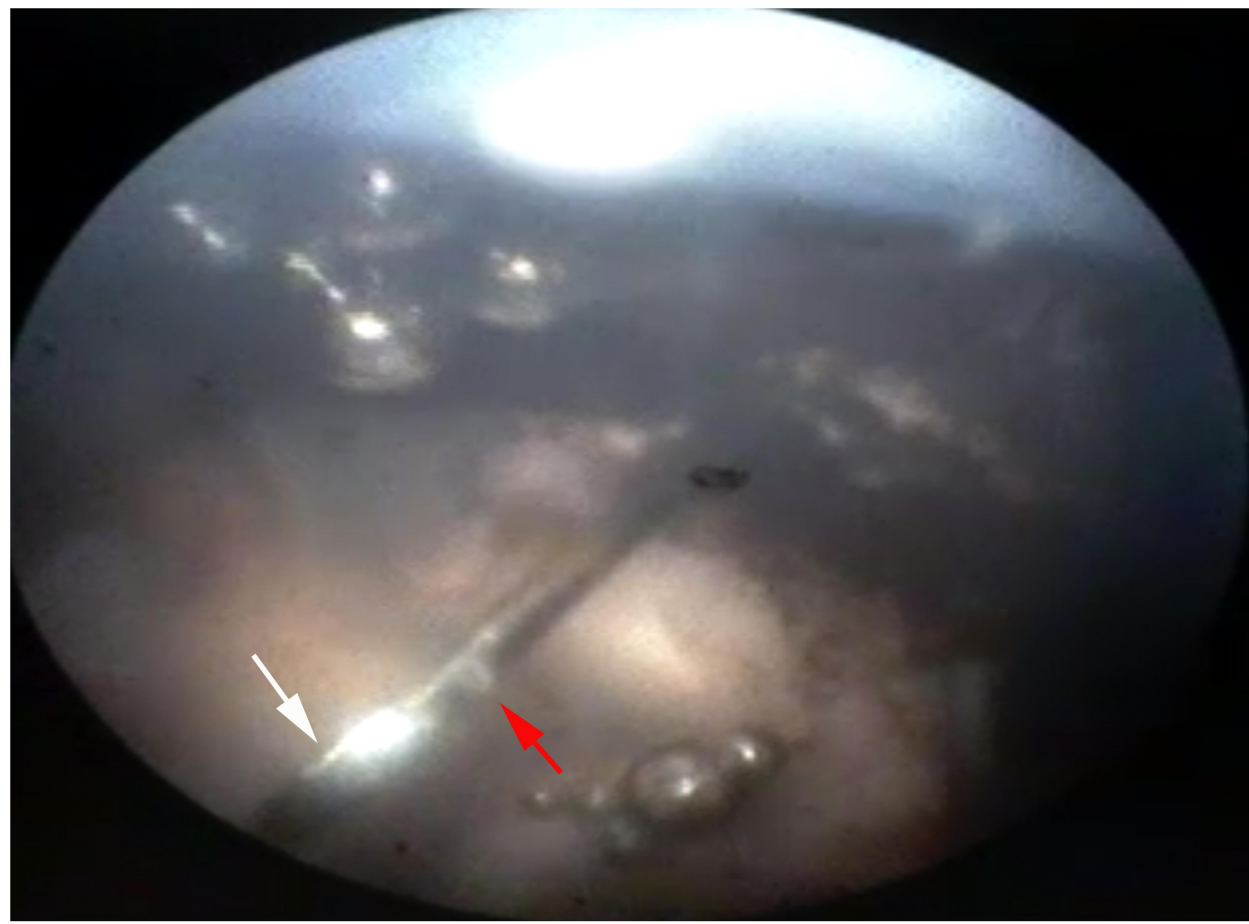

Figure 3 Enlarged view of the NDN tip after being inserted into the vitreous cavity of the cadaver pig eye (imaging performed with an E4 Ophthalmic Endoscopy System Endo Optiks ${ }^{\circledR}$ ). Light reflection depicts closed front opening (white arrow). Red arrow indicates side port of the NDN. (Created by L. Lytvynchuk.)
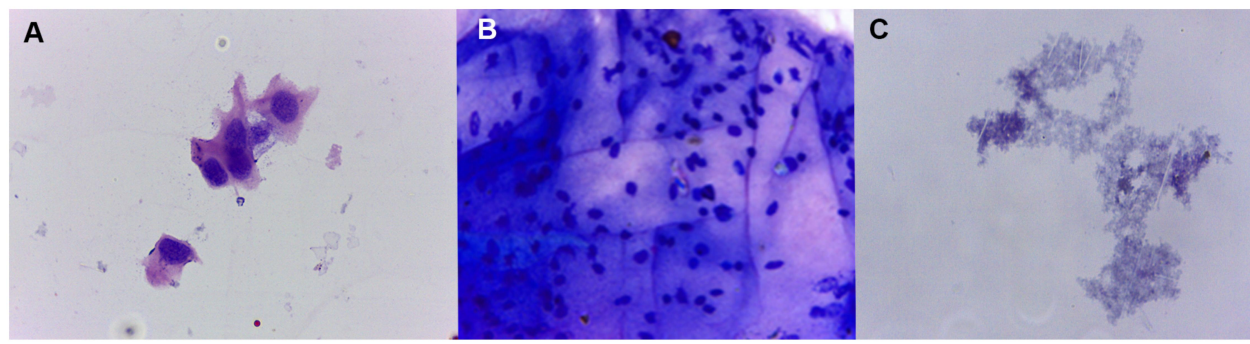

Figure 4 Cells revealed from needle tip aspirates after IVls were performed on rat eyes. Conjunctival epithelial cells (A), ciliary body epithelial cells (B) and granulated basophilic protein sediments (C) were found in aspirates taken from both needle types (magnification $400 \times$, staining with azure-2-eosin). (Created by L. Lytvynchuk.)

dye (Figure 5F). Consequently, the blue dye spreads around the needle tip (Figure 5G) in multiple directions, to then fill out the vitreous cavity in the area of the IVI, similar to the SHN (Figure 5H and Supplementary video 3 ).

\section{Penetration Force}

The average penetration force of the NDN was $0.791 \mathrm{~N}$. In the case of SHN, it was $0.566 \mathrm{~N}$ (Table 2). The average penetration force of the NDN was $39.8 \%$ higher compared to that of the SHN (Figure 6). The average puncture travel

Table I Comparison of the Number of Cells Revealed in the Needle Tip Aspirates After IVIs Were Performed on Rat Eyes, Including Conjunctival Epithelial Cells, Ciliary Body Epithelial Cells and Granulated Basophilic Protein Sediments

\begin{tabular}{|l|c|c|c|}
\hline & Conjunctival Cells, $\mathbf{n}$ & Ciliary Body Epithelium, $\mathbf{n}$ & Granulated Proteins, $\mathbf{n}$ \\
\hline Standard needle & $106^{*}$ & $14^{*}$ & $1442.75^{*}$ \\
New needle & $48^{*}$ & $7^{*}$ & $885.3^{*}$ \\
\hline
\end{tabular}

Note: $*_{p}<0.05$. 


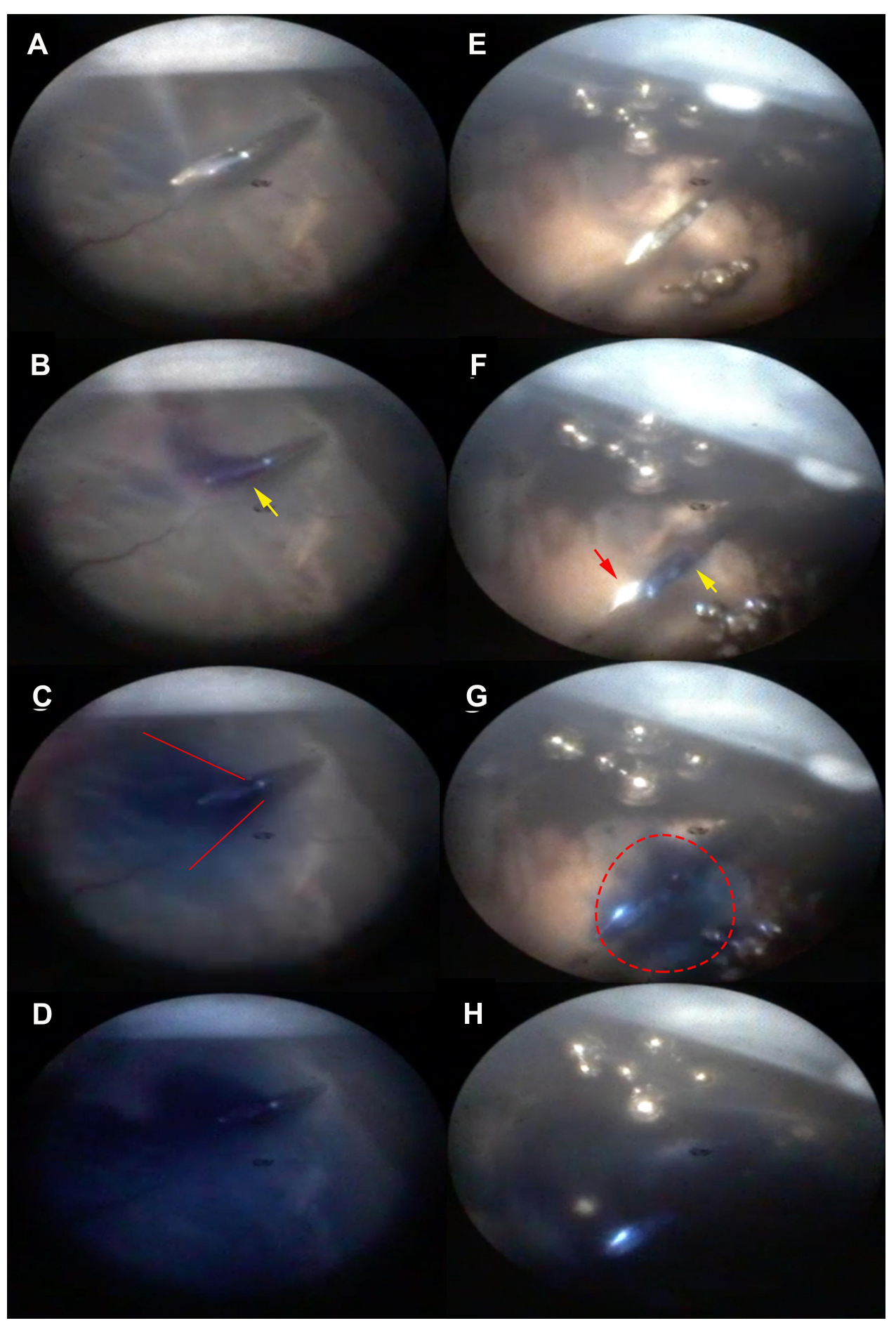

Figure 5 Comparison of the injection stream during IVI with the SHN (A-D) and the NDN (E-H) in cadaver pig eyes. During the initial IVI stage the dye appears on the needle tip of the SHN (B, yellow arrow) and on the side of the NDN needle (F, yellow arrow) while the needle tip remains free of dye (F, red arrow). The dye spreads in conical manner from the SHD (C, red lines) and it spreads around the needle tip of the NDN (G, dashed line). Diffuse filling of the vitreous of the injection site appears to be similar in the case of the SHN and NDN. (Created by L. Lytvynchuk.)

of the needle tip of the NDN was $2.9 \mathrm{~mm}$ (Figure 6). The average puncture travel of the needle tip of the SHN was $2.3 \mathrm{~mm}$ (Figure 6). In these initial tests, the SHN performed, on average, better than the NDN. However, due to the small sample size, it is not possible to attach statistical significance to these values $(p>0.05)$. 
Table 2 Comparison of the Penetration Force Measured for the Injection Performed by the NDN and SHN Types

\begin{tabular}{|l|c|c|c|}
\hline Needle Type & Test, number & Maximum Force (N) & Average Maximum Force (N) \\
\hline Standard hypodermic needle & 1 & 0.655 & $0.566^{*}$ \\
& 2 & 0.511 & \\
& 3 & 0.533 & \\
\hline Newly designed needle & 6 & 0.709 & $0.79 I^{*}$ \\
& 7 & 0.763 & \\
\hline
\end{tabular}

Note: ${ }^{*} p>0.05$.

\section{Discussion}

The IVI technique has become the most commonly utilized drug delivery route in the treatment of different eye diseases including intraocular inflammation, retinoblastoma and a variety of neovascular disorders of the anterior and posterior eye segments. ${ }^{1,2,6-9,45}$ The number of diseases which can be treated with different pharmaceutical agents delivered intravitreally is constantly growing, as well as the number of patients who receive IVIs. Despite the low rate of visionthreatening complications, the actual number of patients experiencing complications caused by IVIs appears to be increasing. ${ }^{46}$ Hence, improvement of the IVI technique and perfection of the required instrumentation remain the focus of numerous studies aimed to reduce the rate of complications. ${ }^{47-51}$ Since the last decade, a number of different devices for IVI were proposed and introduced into clinical practice. Among the main issues which hypothetically could reduce the complication rates associated with IVIs are the stability of the eye, enhanced sterility of the injected area, diameter of the needle and premeasured distance from the limbus, which are all required for safe procedures. ${ }^{52,53}$ To the best of our knowledge, there is no study dedicated to the modification of the needle tip design. Improvement of the safety of the IVI technique through modification of the needle tip was therefore the main aim of our study.

The study results demonstrated that use of standard hypodermic needles for IVI could be associated with an unintentional injection of a certain amount of biologically active or contaminated cellular content, which is cut by the sharp edges of the needle tip during the penetration of the eye wall. In clinical settings, this event can lead to the development of aseptic or septic inflammation. Application of a novel needle for IVIs with occluded front opening and side port is hereby shown to cause significantly less trauma to the eye wall with less cellular damage in experimental conditions. The injection stream of the novel needle allowed delivery of the blue dye into the vitreous cavity quite effectively and similar to a standard hypodermic needle. Comparison of the penetration forces of both needles revealed slight superiority of the SHN over the NDN. However, this can be explained by the manufacturing of the NDN prototypes based on the SHN, which was performed in a technical laboratory.

Application of needles with a side port and modified needles have been applied in different branches of medicine,

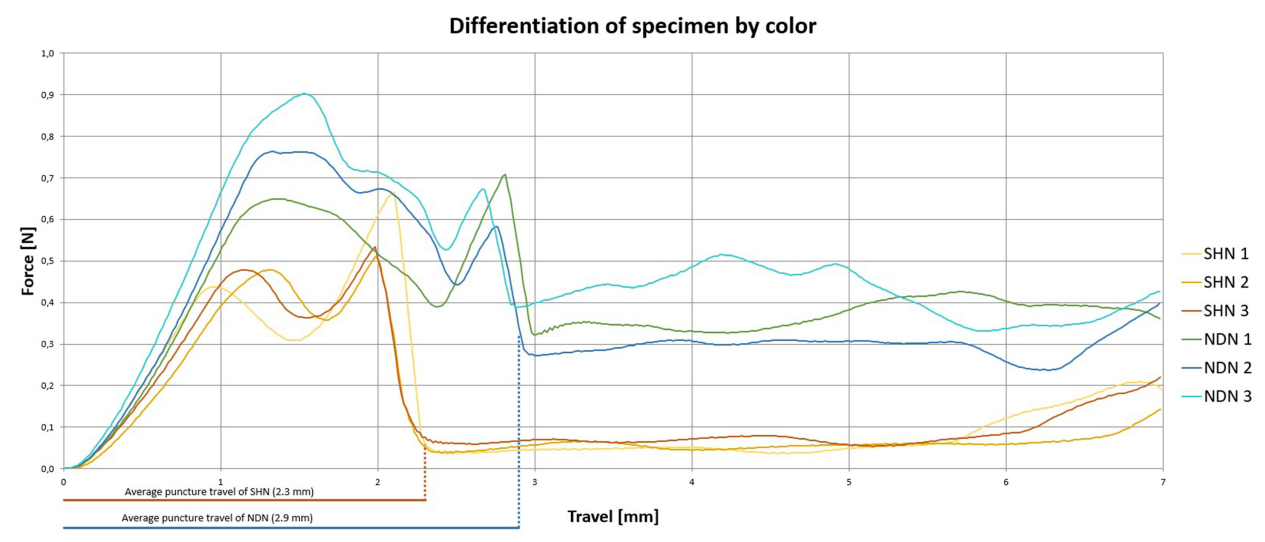

Figure 6 Penetration resistance of the NDN and SHN measured and plotted as a load-displacement diagram. Each needle type was tested three times: yellow, orange and red lines - for the SHN; green, blue and turquoise lines - for the NDN. Ddashed lines indicate an average puncture travel of the needle tips: red dashed line for the SHN $(2.3 \mathrm{~mm})$, blue dashed line for the NDN $(2.9 \mathrm{~mm})$. (Created by J. Hiemstra.) 
including anesthesiology, dentistry and ophthalmology. ${ }^{54-58}$ Several studies report the use of modified infusion and injection cannulas with a blunt tip and a side port for vitreoretinal surgery, which aim to assist during complex surgical procedures, providing safety and decreasing the risk for retinal damage. ${ }^{57,58}$ The caliber of such needles ranges from 23 to 27 gauge, and they have been used through preperformed sclerotomies with the same size previously.

Improvement of the needle tip for IVI design has been reported earlier as well. Meyer et al compared the geometry, penetration force and cutting profile of the novel and standard needles of the drug delivery system for injections of a dexamethasone-containing implant (DEX-implant; OZURDEX, Allergan, Inc., Irvine, CA, USA). ${ }^{39}$ The study concluded that enhanced geometry of the needle tip could significantly improve the cutting profile through reduced penetration forces in experimental conditions. Hence, the IVI of the OZURDEX implant in humans could be performed in a smoother manner. The authors measured the penetration resistance which included few phases: piercing, cutting, sliding and dilatation. The latter study compared convectional and new needle types, which had a hypodermic-like design of the tip with sharp outer and inner edges with a 22-gauge needle caliber, necessary for the implantation of the OZURDEX implant. In our study, an alternative needle tip was compared to a conventional needle with a 30 -gauge caliber. The penetration forces of both needle types in our study were measured in Newtons $(\mathrm{N})$ as a penetration resistance value, and then plotted as a load-displacement diagram without subdivision into different phases.

Recent reports have also compared the patients' experience during IVIs using different calibers of needles. ${ }^{59,60,61}$ In 2018, Aderman et al reported results of the comparison of $33 \mathrm{G}$ versus $30 \mathrm{G}$ needles for IVI. ${ }^{59}$ The study focused on the possible advantages of a smaller gauge needle due to its theoretical ability to decrease patient discomfort, as well as decrease the risk of infection, and minimize reflux of the injected drug. The latter study showed no significant difference between two ( $30 \mathrm{G}$ and $33 \mathrm{G}$ ) needle types in regards to the overall mean pain score in all subgroups (gender, diagnosis, age), while it revealed potential disadvantages of the $33 \mathrm{G}$ needle such as increased intraocular pressure (reduced reflux) and increased cost. In 2018, Sasajima et al reported the results of a randomized clinical trial of using short $34 \mathrm{G}$ needles for IVI. ${ }^{62}$ The authors concluded that the $34 \mathrm{G}$ short needle significantly reduces pain during the IVI procedure. In spite of the immediate transient elevations of intraocular pressure, the lower rate of reflux could improve the precision of the drug dosing as well. Like other studies in the past, the focus has been placed on the possible benefits of new needles with smaller diameter and shorter length, using the same hypodermic-like design of the needle tip. Our study is unique in the sense that it analyzes the performance of two needle types with the same caliber $(30 \mathrm{G})$, but a different needle tip design.

In order to improve the accuracy of the IVI procedure, the IVI assistant Precivia ${ }^{\circledR}\left(\mathrm{FCI}^{\circledR}\right.$, Paris, France) and the InVitria (FCI Ophthalmics, Pembroke, MA, USA) were introduced into clinical practice, which makes the procedure easier, faster and more predictable. ${ }^{52}$ Likewise, a SP. eye $^{\mathrm{TM}}$ IVI assistant (Andersen Caledonia Ltd, North Lanarkshire, Scotland) which integrates an intravitreal delivery guide and sharp safe system for IVI is also available on the market. ${ }^{53}$ It is stated that this device provides sharpness, precision of injection and stability on the eye surface, and it may be used with standard hypodermic 30 $\mathrm{G}$ needles for trans-pars plana IVI of any medication. All available devices for IVI, however, although focusing on improved safety, do not address the issue of improving the needle tip design.

Development of new drug delivery devices, which can maintain the necessary concentration of drugs in the vitreous cavity over a longer period of time and which can be refilled, could minimize the use of needles for IVI. Among them, there is an implantable drug delivery pump - the Posterior MicroPump Drug Delivery System (PMP, Replenish Inc., Pasadena, CA, USA), which has already been tested in 11 patients with diabetic macular edema and appeared well tolerated over 3 months. ${ }^{63}$ This technology uses a microelectromechanical system for drug delivery, which can reliably deliver 100 programmed anti-VEGF doses accordingly. In an animal study, it was shown that the performance of this system is equivalent to $>8$ years of continuous IVI therapy.

Another clinical trial studied the efficacy of a refillable ranibizumab port delivery system in patients with a neovascular form of AMD (Lucentis, Genentech), which consists of a sustained release reservoir (the study has now passed phase 1). ${ }^{64,65}$ This system is aimed to reduce the number of required repeated IVIs. The study also showed that the mean number of system refills was 4.8/patient/12 months. A clear disadvantage of this system is the need for surgical implantation of the preloaded implant through a $3.2 \mathrm{~mm}$ pars plana incision and 
a consequent conjunctival covering, which can increase the rate of postoperative risks.

An alternative drug delivery route is the subconjunctival injection of biodegradable microspheres, which can substitute for the frequently repeated IVIs. ${ }^{66}$ This technology has been tested in rats to treat experimental diabetic retinopathy. When loaded with celecoxib microsphere carriers and injected into the subconjunctival space, this drug delivery system could decrease the elevated diabetesinduced concentration of VEGF in the rats.

Development of new drug delivery systems is intended to decrease the number of standard IVI procedures, which are required by a wide range of eye diseases. If these new methods will succeed, the need for a new needle type for IVI will likely be doubted. However, there is still no alternative drug delivery system which is approved for everyday clinical use, while the introduction of conceptually new injection systems or methods can certainly increase the cost for such a treatment. Additionally, due to the lack of long-term follow-up in regard to postoperative complications of using the new and alternative drug delivery systems, one can agree that the improved needle tip approach would be safe, effective and practical to use.

Special attention has to be given to the reduction of the pain and discomfort in patients who receive multiple IVIs. A number of studies demonstrated that smaller needles with caliber of 31-33 gauge may offer advantages during IVI performance over standard 27- and 30-gauge needles. $^{35,67,68}$ Moreover, there is a possibility to reduce the caliber of the new designed needle prototypes to 31 or 33 gauge in future studies in order to make IVI less traumatic to ocular tissues and to study patients' pain score and comfort.

Our study has some limitations. The manufacturing of the prototypes of the NDN was performed in a workshop of a supporting company and was done only for experimental purposes. We assume that the actual penetration force of the NDN is thus lower. The limited number of prototypes produced could be another limitation of this study, as the larger number of experiments could give us a possibility to interpret the study results more precisely. Therefore, a further experimental study of NDN use after a more accurate manufacturing process and a larger number of prototypes would certainly be necessary. Additionally, investigation of how the change of the stream direction could influence the substance of the drug at a molecular level, and in particular the anti-VEGF antibodies, could increase our knowledge about the performance of NDN during IVIs.

\section{Conclusions}

Overall, the results of this study propose a new design of the needle tip for use in IVIs, which can reduce ocular tissue trauma and significantly decrease capture of the cellular content inside the needle tip. Cytological study of needle tip aspirates demonstrated almost 50\% less cellular content discovered from the NDN in comparison to the SHN. The required penetration force of the prototype NDN was higher than that of the SHN, which would need to be solved through an improved good manufacturing process. The role of the cellular content, which could be potentially injected into the vitreous, has to be taken into consideration. Clinical significance of the new design of the needle prototype shall be further investigated.

\section{Acknowledgments}

Preliminary data of this study were presented at the ARVO Annual Meeting 2019 (Vancouver, Canada) as a poster talk with interim findings. The poster's abstract was published as ARVO Annual Meeting Abstract in Investigative Ophthalmology \& Visual Science Journal July 2019, Vol. 60, 5753 (https://iovs.arvojournals.org/article.aspx?arti cleid=2744944). Mr. Vasyl Didenko (Kyiv, Ukraine) for co-manufacturing of the needle prototype, Anke Malitte (Köln, Germany) for graphic presentation of the needle.

\section{Disclosure}

Lyubomyr M. Lytvynchuk reports a patent EP 18158542.3 pending. The authors report no other conflicts of interest in this work.

\section{References}

1. Fagan XJ, Al-Qureshi S. Intravitreal injections: a review of the evidence for best practice. Clin Exp Ophthalmol. 2013;41(5):500-507. doi:10.1111/ceo.12026

2. Campbell RJ, Bronskill SE, Bell CM, Paterson JM, Whitehead M, Gill SS. Rapid expansion of intravitreal drug injection procedures, 2000 to 2008: a population-based analysis. Arch Ophthalmol. 2010;128(3):359-362. doi:10.1001/archophthalmol.2010.19

3. Karth PA, Blumenkranz MS. Update on intravitreal injection techniques: on the anniversary of the consensus guidelines, a look at what evidence gathered over the decade has taught us. Rev Opthalmol. 2014;21:81-85.

4. Hartman RR, Kompella UB. Intravitreal, Subretinal, and suprachoroidal injections: evolution of microneedles for drug delivery. $J$ Ocul Pharmacol Ther. 2018;34(1-2):141-153. doi:10.1089/jop.2017.0121

5. Avery RL, Bakri SJ, Blumenkranz MS, et al. Intravitreal injection technique and monitoring: updated guidelines of an expert panel. Retina. 2014;34:S1-S18. doi:10.1097/IAE.0000000000000399 
6. Shikari H, Samant PM. Intravitreal injections: a review of pharmacological agents and techniques. J Clin Ophthalmol Res. 2016;4 (1):51-59. doi:10.4103/2320-3897.174429

7. Durand ML. Bacterial and fungal endophthalmitis. Clin Microbiol Rev. 2017;30(3):597-613. doi:10.1128/CMR.00113-16

8. Qian Z, Li H, Tao Y, Li W. Initial intravitreal injection of high-dose ganciclovir for cytomegalovirus retinitis in HIV-negative patients. BMC Ophthalmol. 2018;18(1):314. doi:10.1186/s12886-018-0983-z

9. Manjandavida FP, Shields CL. The role of intravitreal chemotherapy for retinoblastoma. Indian $J$ Ophthalmol. 2015;63(2):141-145. doi:10.4103/0301-4738.154390

10. Moisseiev E, Loewenstein A. [Intravitreal injection - a small procedure for the eye, a giant leap for ophthalmology]. Harefuah. 2019;158(2):121-125. Hebrew.

11. Van der Reis MI, La Heij EC, De Jong-hesse Y, Ringens PJ, Hendrikse F, Schouten JSAG. A systematic review of the adverse events of intravitreal anti-vascular endothelial growth factor injections. Retina. 2011;31(8):1449-1469. doi:10.1097/ IAE.0b013e3182278ab4

12. Sigford DK, Reddy S, Mollineaux C, Schaal S. Global reported endophthalmitis risk following intravitreal injections of anti-VEGF: a literature review and analysis. Clin Ophthalmol. 2015;9:773-781. doi:10.2147/OPTH.S77067

13. Jonas JB, Spandau UH, Rensch F, Von Baltz S, Schlichtenbrede F. Infectious and noninfectious endophthalmitis after intravitreal bevacizumab. J Ocul Pharmacol Ther. 2007;23(3):240-242. doi:10.1089/jop.2006.0146

14. Klein KS, Walsh MK, Hassan TS, et al. Endophthalmitis after anti-VEGF injections. Ophthalmology. 2009;116(6):1225-e1. doi:10.1016/j.ophtha.2009.02.031

15. Cheung CSY, Wong AWT, Lui A, Kertes PJ, Devenyi RG, Lam W-C. Incidence of endophthalmitis and use of antibiotic prophylaxis after intravitreal injections. Ophthalmology. 2012;119(8):1609-1614. doi:10.1016/j.ophtha.2012.02.014

16. Benoist d'Azy C, Pereira B, Naughton G, Chiambaretta F, Dutheil F. Antibioprophylaxis in prevention of endophthalmitis in intravitreal injection: a systematic review and meta-analysis. PLoS One. 2016;11 (6):e0156431. doi:10.1371/journal.pone.0156431

17. Budzinskaya MV, Khalatyan AS, Strakhovskaya MG, Zhukhovitsky VG. Ocular flora in patients undergoing intravitreal injections: antibiotic resistance patterns and susceptibility to antiseptic picloxydine. Int J Ophthalmol. 2020;13(1):85-92. doi:10.18240/ ijo.2020.01.13

18. Goldberg RA, Shah CP, Wiegand TW, Heier JS. Noninfectious inflammation after intravitreal injection of aflibercept: clinical characteristics and visual outcomes. Am J Ophthalmol. 2014;158(4):7337.e1. doi:10.1016/j.ajo.2014.06.019

19. Diago T, Mccannel CA, Bakri SJ, Pulido JS, Edwards AO, Pach JM. Infectious endophthalmitis after intravitreal injection of antiangiogenic agents. Retina. 2009;29(5):601-605. doi:10.1097/ IAE.0b013e31819d2591

20. Friedman DA, Lindquist TP, Mason JOI, McGwin G. Needle contamination in the setting of intravitreal injections. Retina. 2014;34 (5):929-934. doi:10.1097/IAE.0000000000000067

21. De Caro JJ, Ta CN, Ho H-KV, et al. Bacterial contamination of ocular surface and needles in patients undergoing intravitreal injections. Retina. 2008;28(6):877-883. doi:10.1097/IAE.0b013e31816b3180

22. Tufan HA, Vural A, Gencer B, Kara S, Arikan S, Yuksel E. Bacterial contamination of needles used for intravitreal injections: comparison between 27-gauge and 30-gauge needles. Ocul Immunol Inflamm. 2013;21(5):366-370. doi:10.3109/09273948.2013.801988

23. Stewart JM, Srivastava SK, Fung AE, et al. Bacterial contamination of needles used for intravitreal injections: a prospective, multicenter study. Ocul Immunol Inflamm. 2011;19(1):32-38. doi:10.3109/ 09273948.2010 .520405
24. Lytvynchuk L, Sergienko A, Savytska I, et al. Comparative cyto-histological study of needle tip aspirates and entry sites after intravitreal injection using different needle types. PLoS One. 2017;12 (7):e0174467. doi:10.1371/journal.pone.0174467

25. Kucklick TR. Introduction to Needles and Cannulae. Boca Raton, FL 33487-2742: CRC Press Taylor and Francis Group; 2006:90-98.

26. Natividad A, Freeman TC, Jeffries D, et al. Human conjunctival transcriptome analysis reveals the prominence of innate defense in chlamydia trachomatis infection. Infect Immun. 2010;78 (11):4895-4911. doi:10.1128/IAI.00844-10

27. Forrester JV, Docherty R, Kerr C, Lackie JM. Cellular proliferation in the vitreous: the use of vitreous explants as a model system. Invest Ophthalmol Vis Sci. 1986;27(7):1085-1094.

28. Speaker MG, Milch FA, Shah MK, Eisner W, Kreiswirth BN. Role of external bacterial flora in the pathogenesis of acute postoperative endophthalmitis. Ophthalmology. 1991;98(5):639-650. doi:10.1016/ S0161-6420(91)32239-5

29. Scott IU, Flynn HW. Reducing the risk of endophthalmitis following intravitreal injections. Retina. 2007;27(1):10-12. doi:10.1097/ IAE.0b013e3180307271

30. de Stefano VS, Abechain JJK, de Almeida LFS, et al. Experimental investigation of needles, syringes and techniques for intravitreal injections. Clin Experiment Ophthalmol. 2011;39(3):236-242. doi:10.1111/j.1442-9071.2010.02447.x

31. Brodie FL, Ruggiero J, Ghodasra DH, Hui JZ, VanderBeek BL, Brucker AJ. Volume and composition of reflux after intravitreal injection. Retina. 2014;34(7):1473-1476. doi:10.1097/ IAE.0000000000000098

32. Hubschman J-P, Coffee RE, Bourges J-L, Yu F, Schwartz SD. Experimental model of intravitreal injection techniques. Retina. 2010;30(1):167-173. doi:10.1097/IAE.0b013e3181b094cf

33. Christensen L, Cerda A, Olson JL. Real-time measurement of needle forces and acute pressure changes during intravitreal injections. Clin Exp Ophthalmol. 2017;45(8):820-827. doi:10.1111/ceo.12963

34. Rodrigues EB, Grumann AJ, Penha FM, et al. Effect of needle type and injection technique on pain level and vitreal reflux in intravitreal injection. J Ocul Pharmacol Ther. 2011;27(2):197-203. doi:10.1089/ jop. 2010.0082

35. van Asten F, van Middendorp H, Verkerk S, et al. Are intravitreal injections with ultrathin $33-\mathrm{G}$ needles less painful than the commonly used 30-G needles? Retina. 2015;35(9):1778-1785. doi:10.1097/ IAE.0000000000000550

36. Sasajima H, Tsuboi K, Murotani K, Kamei M. Efficacy and safety of intravitreal drug injections using a short 34-gauge needle. Jpn J Ophthalmol. 2019;63(3):269-275. doi:10.1007/s10384-019-00663-w

37. Eaton AM, Gordon GM, Booth D, Wafapoor H, Avery RL, Hickingbotham D. In vivo and in vitro force testing of a new guarded injection device. Invest. Ophthalmol. Vis. Sci. 2015;56(4):2. doi:10.1167/iovs.14-14803

38. Pulido JS, Zobitz ME, An KN. Scleral penetration force requirement for commonly used intravitreal needles. Eye. 2007;21(9):1210-1211. doi:10.1038/sj.eye. 6702577

39. Meyer CH, Liu Z, Brinkmann CK, Rodrigues EB, Bertelmann T. German retinal vein occlusion group. Penetration force, geometry, and cutting profile of the novel and old ozurdex needle: the MONO study. J Ocul Pharmacol Ther. 2014;30(5):387-391. doi:10.1089/ jop.2013.0231

40. McGrath D Intravitreal injections: new device aims to make intravitreal injections safe and repeatable. Eurotimes. 2015;28-29.

41. Zhang Y, Bazzazi H, Lima E, et al. three-dimensional transport model for intravitreal and suprachoroidal drug injection. Invest Ophthalmol Vis Sci. 2018;59(12):5266-5276. doi:10.1167/iovs.1723632

42. Eichenbaum D My switch to new needles for intravitreal injection. Retina Today. 2019;38-39. 
43. Pearce W, Hsu J, Yeh S. Advances in drug delivery to the posterior segment. Curr Opin Ophthalmol. 2015;26(3):233-239. doi:10.1097/ ICU.0000000000000143

44. Özkaya A, Alkin Z, Celik U, et al. Comparing the effects of three different intravitreal injection techniques on vitreous reflux and intraocular pressure. $J$ Ocul Pharmacol Therap. 2013;29 (3):325-329. doi:10.1089/jop.2012.0144

45. Dugel P, Bandello F, Loewenstein A. Dexamethasone intravitreal implant in the treatment of diabetic macular edema. Clin Ophthalmol. 2015;9:1321-1335. doi:10.2147/OPTH.S79948

46. Nentwich M, Yactayo-Miranda Y, Weimann S, et al. Bacterial contamination of needle points after intravitreal injection. Eur J Ophthalmol. 2009;19(2):268-272. doi:10.1177/112067210901900215

47. Nuzzi R, Scalabrin S, Becco A. Reduction of Intraocular pressure spikes due to intravitreal bevacizumab injections by scleral indentation with cotton swab or digital ocular massage: innovative techniques compared. Clin Ophthalmol. 2020;14:2533-2541. doi:10.2147/ OPTH.S263474

48. Han J, Rinella NT, Chao DL. Anesthesia for intravitreal injection: a systematic review. Clin Ophthalmol. 2020;14:543-550. doi:10.2147/OPTH.S223530

49. Frenkel RE, Haji SA, La M. A protocol for the retina surgeon's safe initial intravitreal injections. Clin Ophthalmol. 2010;4:1279-1285. doi:10.2147/OPTH.S12846

50. Tailor R, Beasley R, Yang Y, Narendran N. Evaluation of patients' experiences at different stages of the intravitreal injection procedure what can be improved? Clin Ophthalmol. 2011;5:1499-1502. doi:10.2147/OPTH.S24358

51. Lai TY, Liu S, Das S, Lam DS. Intravitreal injection-Technique and safety. Asia Pac J Ophthalmol (Phila). 2015;4(6):321-328. doi:10.1097/APO.0000000000000146

52. Blyth M, Innes W, Mohsin-Shaikh N, Talks JA. Comparison of conventional intravitreal injection method vs invitria intravitreal injection method. Clin Ophthalmol. 2020;14:2507-2513. doi:10.2147/OPTH.S238529

53. Soh YQ, Chiam NPY, Tsai ASH, et al. Intravitreal injection with a conjunctival injection device: a single-center experience. Trans Vis Sci Tech. 2020;9(8):28. doi:10.1167/tvst.9.8.28

54. Braun B. Spinal needle for spinal and diagnostic puncture [homepage on the Internet]. Available from: https://www.bbraun.com/en/pro ducts/b1/pencan.html. Accessed November 25, 2020.

55. Ready LB, Kozody R, Barsa JE, Murphy TM. Side-port needles for stellate ganglion block regional Anesthesia. Reg Anesth. 1982;7:160-163.

56. Gündoğar M, Sezgin GP, Kaplan SS, Özyürek H, Uslu G, Özyürek T. Postoperative pain after different irrigation activation techniques: a randomized, clinical trial. Odontology. 2020;(Epub ahead of print). doi:10.1007/s10266-020-00553-5
57. Hirata A, Yonemura N, Hasumura T, Murata Y, Negi A, Tanihara H. New infusion cannula for prevention of retinal damage by infusion air during vitrectomy. Retina. 2003;23(5):682-685. doi:10.1097/ 00006982-200310000-00013

58. Mi C, Petersen M, Foster R, Riemann C, Sisk R. New surgical applications for the SideFlo cannula. Retina. 2017;37(2):400-401. doi:10.1097/IAE.0000000000001270

59. Aderman CM, Rahimy E, Obeid A, et al. Comparing 33-gauge versus 30-gauge needles for intravitreal injections. Ophthalmol Retina. 2018;2(10):1078-1079. doi:10.1016/j.oret.2018.05.003

60. Muto T, Machida S. Vitreous reflux frequency and intraocular pressure after first-time intravitreal aflibercept injections: comparison of 30- and 32-gauge needles. Clin Ophthalmol. 2020;14:625-634. doi:10.2147/OPTH.S243370

61. Cernichiaro-Espinosa LA, Harper CA, Read SP, et al. Report of safety of the use of a short $32 \mathrm{G}$ needle for intravitreal anti-vascular endothelial growth factor injections for retinopathy of prematurity: a Multicenter Study. Retina. 2018;38(6):1251-1255. doi:10.1097/ IAE.0000000000002172

62. Sasajima H, Tsuboi K, Ono H, Murotani K, Kamei M. A randomized trial of a short 34-gauge needle for intravitreal injections. Ophthalmology. 2018;125(6):947-948. doi:10.1016/j. ophtha.2018.01.038

63. Humayun M, Santos A, Altamirano JC, et al. Implantable microPump for drug delivery in patients with diabetic macular edema. Transl Vis Sci Technol. 2014;3(6):5. doi:10.1167/tvst.3.6.5

64. Rubio RG Long-Acting Anti-VEGF Delivery. Retina Today. 2014;78-80.

65. Chen ER, Kaiser PK. Therapeutic potential of the ranibizumab port delivery system in the treatment of AMD: evidence to date. Clin Ophthalmol. 2020;14:1349-1355. doi:10.2147/OPTH.S194234

66. Kompella UB, Bandi N, Ayalasomayajula SP. Subconjunctival nanoand microparticles sustain retinal delivery of budesonide, a corticosteroid capable of inhibiting VEGF expression. Invest Ophthalmol Vis Sci. 2003;44(3):1192-1201. doi:10.1167/iovs.020791

67. Haas P, Falkner-Radler C, Wimpissinger B, Malina M, Binder S. Needle size in intravitreal injections - pain evaluation of a randomized clinical trial. Acta Ophthalmol. 2016;94(2):198-202. doi:10.1111/aos. 12901

68. Eaton AM, Gordon GM, Wafapoor H, Sgarlata A, Avery RL. Assessment of novel guarded needle to increase patient comfort and decrease injection time during intravitreal injection. Ophthalmic Surg Lasers Imaging Retina. 2013;44(6):561-568. doi:10.3928/2325816020131105-06
Clinical Ophthalmology

\section{Publish your work in this journal}

Clinical Ophthalmology is an international, peer-reviewed journal covering all subspecialties within ophthalmology. Key topics include: Optometry; Visual science; Pharmacology and drug therapy in eye diseases; Basic Sciences; Primary and Secondary eye care; Patient Safety and Quality of Care Improvements. This journal is indexed on PubMed

\section{Dovepress}

Central and CAS, and is the official journal of The Society of Clinical Ophthalmology (SCO). The manuscript management system is completely online and includes a very quick and fair peer-review system, which is all easy to use. Visit http://www.dovepress.com/ testimonials.php to read real quotes from published authors. 